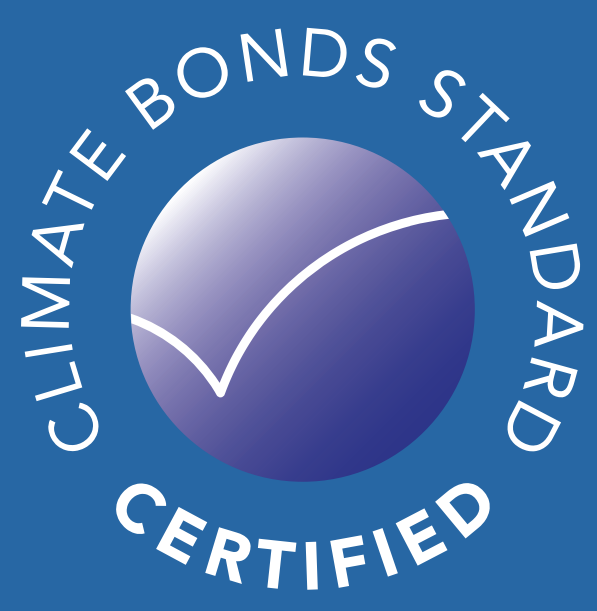

\title{
Climate Bonds
}

\section{Climate Bonds Standard Version 3.0}

\section{International best practice for labelling green investments}

Certification under the Climate Bonds Standard confirms that the bond, loan or other debt instrument is:

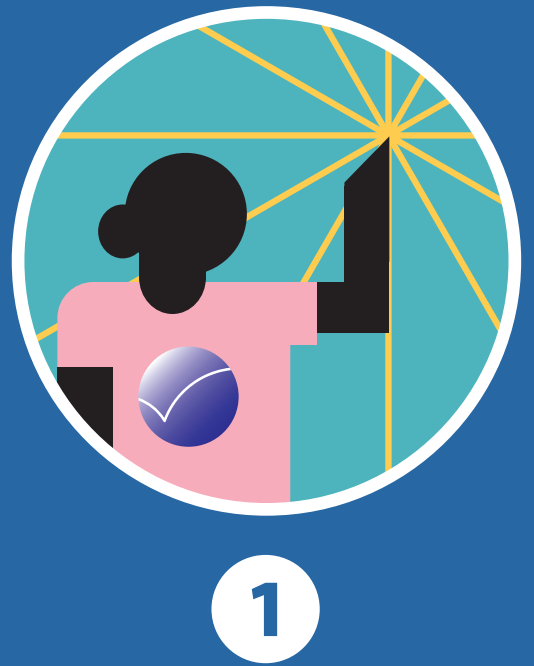

Fully aligned with the Green Bond Principles and/or the Green Loan Principles

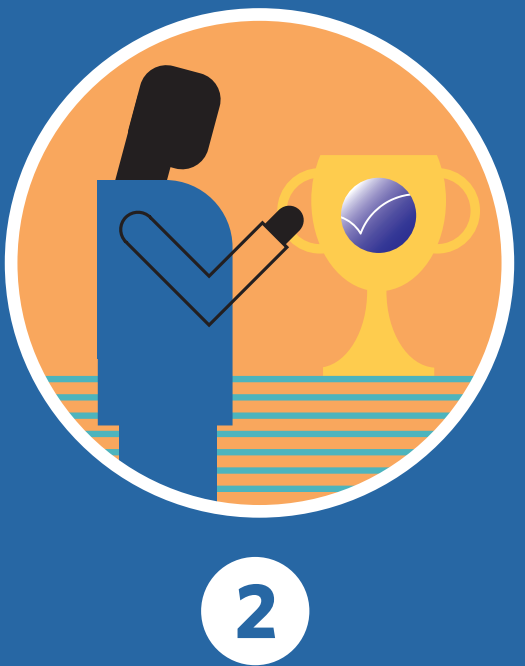

Using best practice for internal controls, tracking, reporting and verification

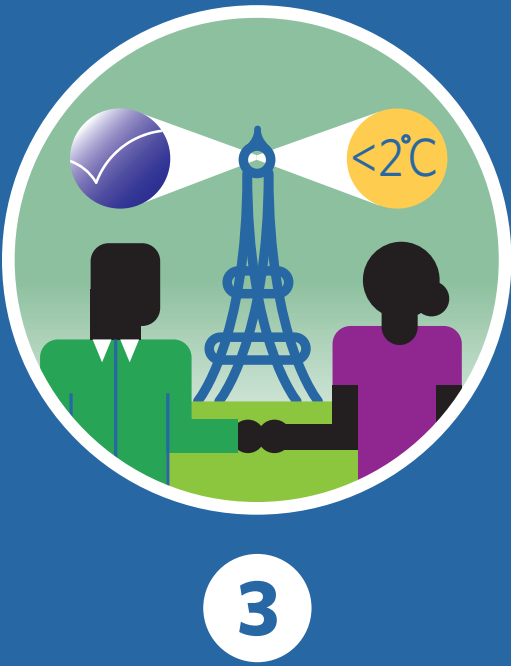

Financing assets consistent with achieving the goals of the Paris Climate Agreement 


\section{Table of Contents}

Introducing the Climate Bonds Standard \& Certification Scheme 3

Definitions 8

\section{Climate Bonds Standard 12}

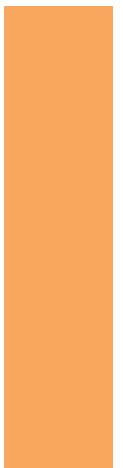

\section{Part A}

Pre-Issuance Requirements 12

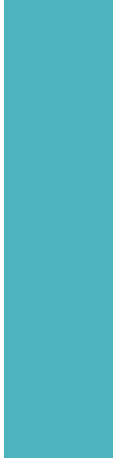

\section{Part B}

Post-Issuance Requirements 16

1. Use of Proceeds 12

2. Process for Evaluation and Selection of Projects \& Assets $\mathbf{1 3}$

3. Management of Proceeds 14

4. Reporting Prior to Issuance $\mathbf{1 4}$

5. Use of Proceeds 16

6. Process for Evaluation and Selection of Projects \& Assets 17

7. Management of Proceeds 17

8. Reporting $\mathbf{1 8}$

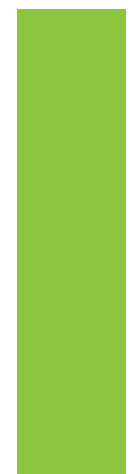

\section{Part C}

Eligibility of Projects \& Assets 22

9. Climate Bonds Taxonomy 22

10. Sector Eligibility Criteria 22

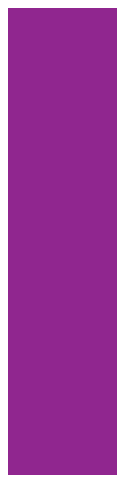

\section{Part D}

Certification under the

Climate Bonds Standard 23

Outline of the Certification Process $\mathbf{2 3}$

Pre-Issuance Certification 24

Post-Issuance Certification $\mathbf{2 6}$

Programmatic Certification 28

Maintaining Certification $\mathbf{2 8}$

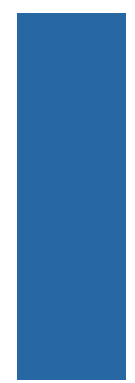

\section{Annex 1:}

Bonds, loans and other debt instruments which can be Certified 30

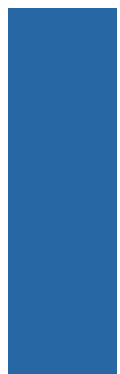

\section{Annex 3:}

Certification and the CBI Green Bond Database Methodology 33

\section{Annex 2: \\ Compatibility between CBS V3.0 and proposed EU Green Bond Standard 32}

Disclaimer: The information contained in this communication does not constitute investment advice in any form and the Climate Bonds Initiative is not an investment adviser. Any reference to a financial organisation or debt instrument or investment product is for information purposes only. Links to external websites are for information purposes only. The Climate Bonds Initiative accepts no responsibility for content on external websites.

The Climate Bonds Initiative is not endorsing, recommending or advising on the financial merits or otherwise of any debt instrument or investment product and no information within this communication should be taken as such, nor should any information in this communication be relied upon in making any investment decision.

Certification under the Climate Bond Standard only reflects the climate attributes of the use of proceeds of a designated debt instrument. It does not reflect the creditworthiness of the designated debt instrument, nor its compliance with national or international laws.

A decision to invest in anything is solely yours. The Climate Bonds Initiative accepts no liability of any kind, for any investment an individual or organisation makes, nor for any investment made by third parties on behalf of an individual or organisation, based in whole or in part on any information contained within this, or any other Climate Bonds Initiative public communication. 


\section{Introducing the Climate Bonds Standard \& Certification Scheme}

The Climate Bonds Initiative is an international investor-focused not-for-profit organisation. It was founded in 2010 to promote large-scale investments that will deliver a low-carbon and climate-resilient global economy. Climate Bonds seeks to mobilise investors, industry and government to catalyse green investments at the speed and scale required to avoid dangerous climate change and meet the goals of the Paris Climate Agreement.

\section{A key component of the Initiative is the Climate Bonds Standard \& Certification Scheme}

"Certification Scheme". The Certification Scheme allows investors, governments and other stakeholders to identify and prioritise 'low-carbon and climate resilient' investments and avoid 'greenwash'.

\section{What does the Certification mark mean?}

Certification under the Climate Bonds Standard confirms that the bond, loan or other debt instrument is:

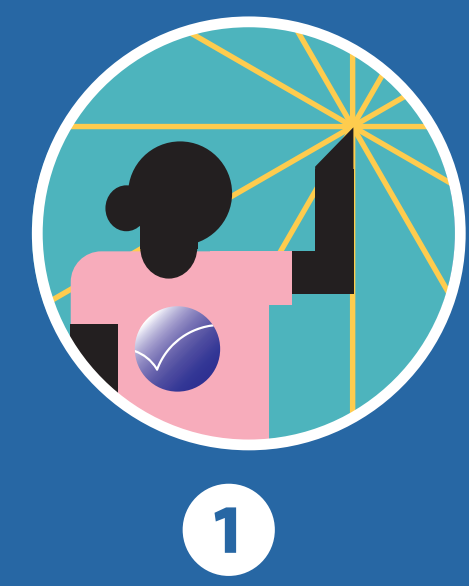

Fully aligned with the Green Bond Principles and/or the Green Loan Principles

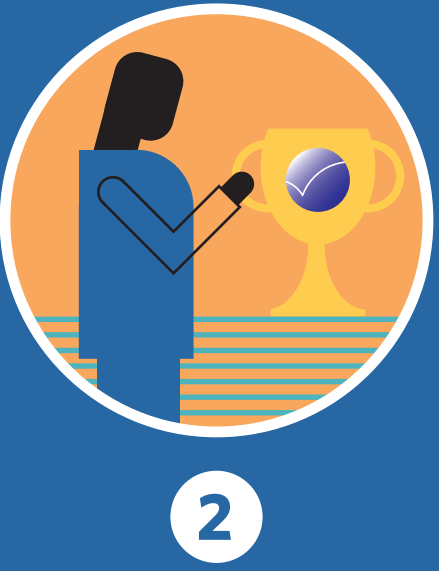

Using best practice for internal controls, tracking, reporting and verification

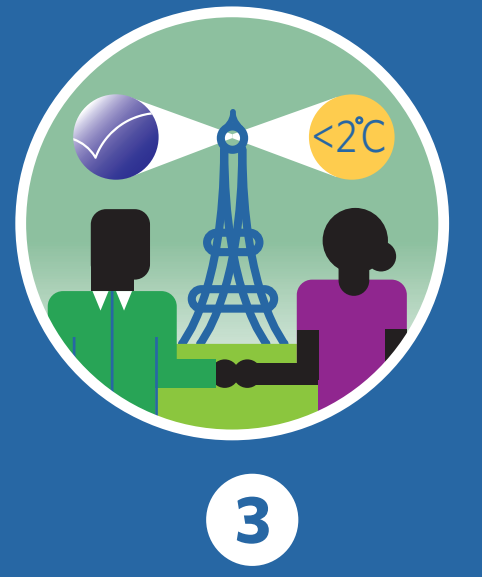

Financing assets consistent with achieving the goals of the Paris Climate Agreement

The Climate Bonds Standard \& Certification Scheme aims to provide the green bond market with the trust and assurance that it needs to achieve scale. Activating the mainstream debt capital markets to finance and refinance climate-aligned projects and assets is critical to achieving international climate goals and robust labelling of green bonds and green loans is a key requirement for that mainstream participation.

While the green finance market continues to grow at pace, future growth relies on maintaining the value of the green label. The green label is underpinned by trust and confidence that the use of funds will be directed to projects and assets that are in line with the Paris Climate Agreement. Investor capacity to assess green credentials is, however, limited, especially in the fast-paced bond/loan market. 
A Scientific Framework underpins the definitions of which projects and assets are consistent with achieving the goals of the Paris Climate Agreement and therefore eligible for inclusion in a Certified Climate Bond, Certified Climate Loan or Certified Climate Debt Instrument. The Certification Scheme includes robust approach for monitoring, reporting and assurance of conformance with the Climate Bonds Standard.

An international Climate Bonds Standard Board comprised of large institutional investors and leading environmental NGOs provides ongoing oversight of the Climate Bonds Standard, Approved Verifiers, the Certification Scheme as well as decisions on Certifications. Day-to-day operations and decision making is delegated to the Climate Bonds Standard Secretariat.

Certification under the Climate Bond Standard relates exclusively to the climate attributes of the bond, loan or other debt instrument, and does not address any other aspect of investment decision-making such as compliance with national or international laws and/or regulations, broader Environment, Social and Governance (ESG) attributes, or creditworthiness.

\section{The Climate Bond Certified Mark "Certification Mark" is used to designate Certified Climate Bonds, Certified Climate Loans and Certified Climate Debt Instruments.}

The Climate Bonds Standard \& Certification Scheme builds on the broad integrity principles contained in the Green Bond Principles ${ }^{2}$ to create a robust, flexible and effective certification system. Key features include:

- Full alignment with the Green Bond Principles, Green Loan Principles, ${ }^{3}$ the proposed EU Green Bond Standard, ASEAN Green Bond Standards, ${ }^{4}$ Japan's Green Bond Guidelines ${ }^{5}$ and India's Disclosure \& Listing Requirements for Green Bonds ${ }^{6}$

- Clear mandatory requirements for use of proceeds, selection of projects \& assets, management of proceeds and reporting

- Sector criteria for determining the low-carbon and climate resilient credentials of projects and assets

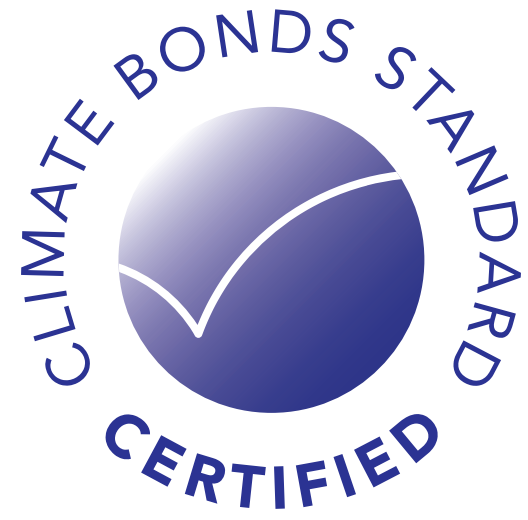

- An assurance framework with independent verifiers and consistent procedures

- Certification awarded by the Climate Bonds Standard Board

- Certification is confirmed after issuance of the bond or loan with mandatory independent verification and annual reporting for the term of the investment

For investors, Certification is a screening tool that labels bonds or loans as Certified Climate Bonds, Certified Climate Loans or Certified Climate Debt Instruments respectively. It reduces the burden for investors having to make subjective judgements during their due diligence on the green attributes of green-labelled investments.

For issuers, Certification is a voluntary initiative, which allows them to clearly demonstrate to the market that their bond or loan meets science-based standards for climate integrity, and best practice standards for management of proceeds and transparency. 


\section{Key Components}

The Climate Bonds Standard \& Certification Scheme comprises of the overarching Climate Bonds Standard Version 3.0 (this document), the Climate Bonds Taxonomy, Sector Eligibility Criteria, guidance material and certification documents.

The Climate Bonds Taxonomy ${ }^{7}$ is the high-level roadmap for the relevant sectors. It forms the basis of the Climate Bonds green bond database methodology, used by Climate Bonds to assess the climate alignment of all green bonds (certified or uncertified) for inclusion in the database, which is then used by index providers, analysts and other market players.

The Sector Eligibility Criteria are science-based and provide detailed definitions for the eligibility of specific projects and assets. The criteria ensure that projects \& assets are consistent with achieving the goals of the Paris Climate Agreement and the rapid transition to a low-carbon \& climate resilient future.

Technical Working Groups and Industry Working Groups provide the expertise for the development of the Sector Eligibility Criteria. The Climate Bonds Standard Board provides governance and oversight of the Standard and the Certification process.

Approved Verifiers provide independent assurance that issuers and their certified bonds or loans have met the requirements of the Standard.

\section{Ongoing Reporting}

All issuers are required to report annually to maintain the Certification of the bond, loan or other debt instrument. The exact nature of the reporting is dependent on the range of underlying projects and assets, and on the issuer's choices.

Reporting to maintain Certification is split into three types: Allocation reporting, Eligibility reporting, and Impact reporting.

- Allocation reporting is confirming the allocation of bond proceeds to eligible projects and assets, and is mandatory for all Certified debt instruments;

- Eligibility reporting is confirming the characteristics or performance of projects and assets to demonstrate their eligibility under the Taxonomy and relevant Sector Eligibility Criteria and is mandatory for all Certified debt instruments.

- Impact reporting is disclosure of metrics or indicators which reflect the expected or actual impact of eligible projects and assets, and is encouraged for all Certified debt instruments, but is not mandatory.

- The three different types of reporting can be included in a single Update Report which must be provided annually while the bond, loan or other debt instrument remains outstanding.

We note that alignment with Sector Eligibility Criteria already provides investors with confidence that the investment is aligned with goals of the Paris Climate Agreement. Given this feature of the standard, the need for detailed and quantitative impact reporting is reduced and often is not necessary. Specific recommendations on impact reporting are provided in a document developed by the Green Bond Principles (GBP) working group on impact reporting, available from the GBP website. ${ }^{8}$ 


\section{How Certification works}

The requirements of the Climate Bonds Standard are separated into the two distinct phases of issuing a bond or closing a loan or other debt instrument:

1. Pre-Issuance Requirements which need to be met for issuers seeking certification ahead of issuance,

2. Post-Issuance Requirements which need to be met by issuers seeking ongoing certification following the issuance.

Certification is also available for bonds, loans or other debt instruments which have already been issued or closed. In these cases, issuers only need to meet the PostIssuance Requirements of the Standard. Issuers can apply for Certification at any time while the debt instrument is outstanding.

Programmatic Certification is available for frequent issuers of Certified deals. This option increases the flexibility and reduces the verification burden for issuers with large scale or longer term green bond or sustainable finance programs.

Verification by an Approved Verifier is mandatory in the Certification process. Ongoing Certification includes requirements for annual reporting with public disclosure.

The Climate Bonds Standard is a climate change standard. It is an authoritative standard that eases decision-making and focuses attention on credible climate change solutions in the debt capital markets.

\section{Resources for the user of the Standard}

All relevant resource documents for the use of the Standard are available on the website link: https://www.climatebonds.net/certification/resources

Climate Bonds Initiative website: https://www.climatebonds.net

Contact Certification team at: certification@climatebonds.net

\footnotetext{
1. The Paris Climate Agreement is an international agreement within the United Nations Framework Convention on Climate Change which entered into effect in November 2016 and will commence in 2020. The goals of the agreement include: "(a) Holding the increase in the global average temperature to well below $2{ }^{\circ} \mathrm{C}$ above pre-industrial levels; (b) Increasing the ability to adapt to the adverse impacts of climate change; (c) Making finance flows consistent with a pathway towards low greenhouse gas emissions and climateresilient development."

2. Green Bond Principles (GBP) are voluntary process guidelines intended for broad use by the market that recommend transparency and disclosure, and promote integrity in the development of the Green Bond market. The latest edition of the GBP is available from the International Capital Markets Association website (www.icmagroup.org/greenbonds). 3. Published by the Loan Market Association (www.Ima.eu.com)

4. Developed by the ASEAN Capital Markets Forum (www.theacmforg)

5. Published by The Ministry of the Environment, Japan and can be retrieved at: http://www.env.go.jp/en/policy/economy/gb/guidelines.html

6. Published by the Securities \& Exchange Board of India (www.sebi.gov.in) and can be retrieved at: https://www.sebi.gov.in/sebi_data/meetingfiles/1453349548574-a.pdf

7. https://www.climatebonds.net/standard/taxonomy

8. https://www.icmagroup.org/green-social-and-sustainability-bonds/impact-reporting/
} 


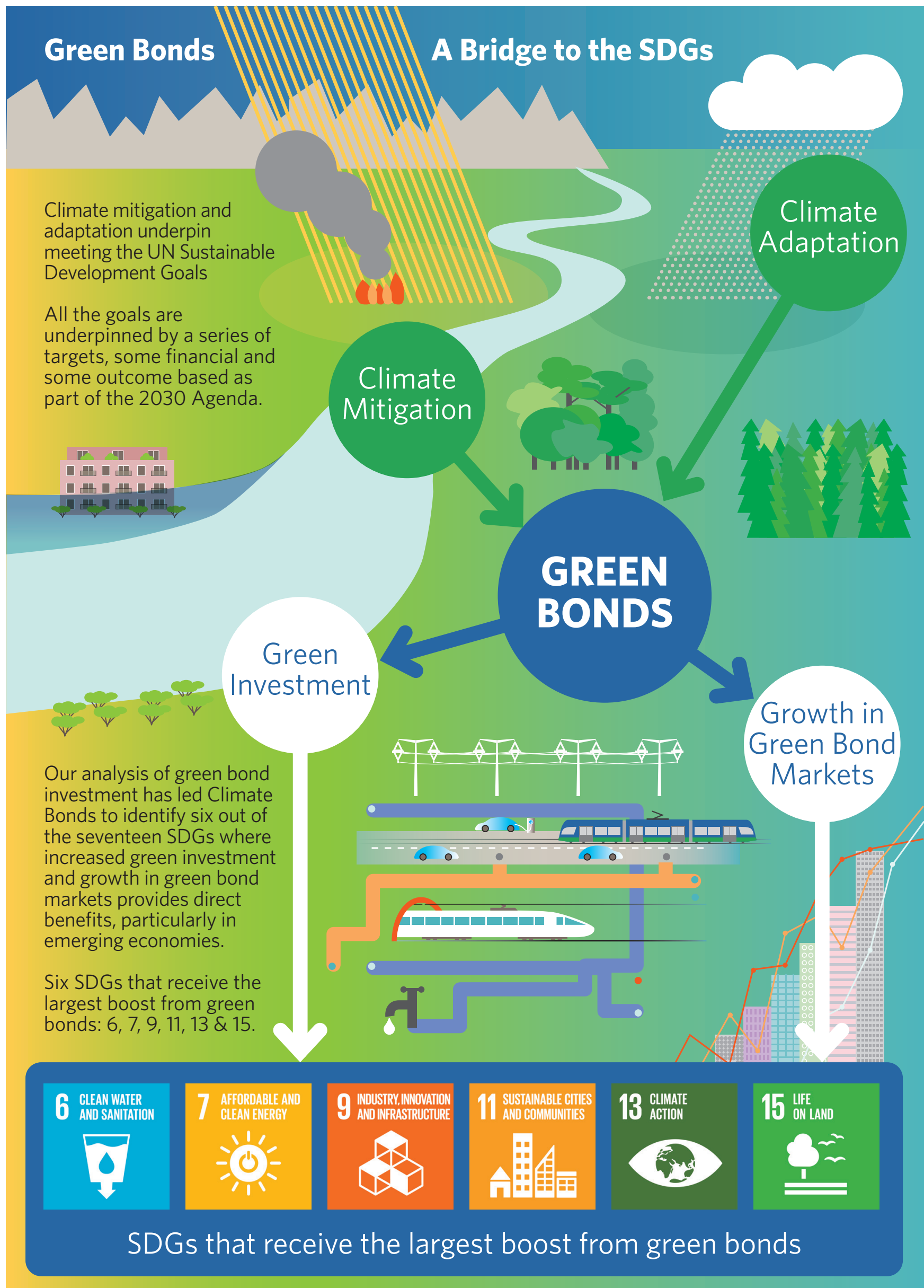




\section{Definitions}

\section{D1. Bonds, loans and other debt instruments}

D1.1 Green Bond, Green Loan or Green Debt Instrument: A bond, loan or other debt instrument where the proceeds will be exclusively applied to finance or re-finance, in part or in full, new and/or existing eligible green projects, and which is aligned with the four core components of the Green Bond Principles or the Green Loan Principles.

A Green Bond, Green Loan or Green Debt Instrument should not be considered fungible or interchangeable with bonds, loans or other debt instruments which are not aligned with those four core components.

\section{D1.2 Certified Climate Bond or Certified Climate Loan or Certified Climate Debt}

Instrument: A green bond, green loan or other green debt instrument that is Certified by the Climate Bonds Standard Board as meeting the requirements of this Climate Bonds Standard.

The term "Bond" is used in this Standard to describe the debt instrument being considered for Certification whether that be structured as a bond or a loan or some other form of debt instrument. Further detail on the types of bonds, loans and other debt instruments which can be Certified under the Climate Bonds Standard is provided in Annex 1.

\section{D2. Standard, certification and structures}

D2.1 Climate Bonds Standard: The requirements and eligibility criteria for Climate Bond Certification, based on the current version as published on the Climate Bonds Initiative resources webpage.

D2.2 Climate Bonds Standard Board: A board of independent members that approves the Standard, Sector Eligibility Criteria and Verifiers, and considers applications for Certification under the Climate Bonds Standard.

Note: The Climate Bonds Standard Board is constituted, appointed and supported in line with the governance arrangements and processes as published on the Climate Bonds Initiative website.

D2.3 Climate Bonds Standard Secretariat: Manages the day-to-day interaction with issuers, verifiers and other stakeholders.

Note: Contact details for the Climate Bonds Standard Secretariat are available on the Climate Bonds Initiative website. Enquiries can be sent via email to certification@ climatebonds.net.

D2.4 Certification under the Climate Bonds Standard: Allows the Issuer to use the Certification Mark in relation to that bond, loan or other debt instrument. Certification is provided once the Climate Bonds Standard Board is satisfied the bond, loan or other debt instrument conforms to the relevant requirements of the Climate Bonds Standard.

D2.5 Certification Mark: The certification logo designating a Certified Climate Bond or Certified Climate Loan or Certified Climate Debt Instrument that Issuers may use once they have obtained Certification from the Climate Bonds Standard Board. Use of the logo by an Issuer is specified within the terms and conditions of the Certification Agreement. 


\section{D3. Issuer, projects \& assets}

D3.1 Issuer: The organisation issuing the bond or other debt instrument; or the borrower and other obligors taking out the loan or other debt instrument, or the financial institution receiving designated deposits. In some circumstances, particularly for portfolios of smaller loans, the lender may take on the role of Issuer in terms of meeting requirements of creating the Green Bond Framework, defining selection criteria, pre-issuance documentation and update reporting.

D3.2 Issuance: The date of issuance for a bond or closing of a loan or other debt instrument.

D3.3 Eligible Projects \& Assets: Parts or collections of:

D3.3.1 Physical assets or projects owned by the Issuer, and/or

D3.3.2 Debt or other financing arrangements provided by the Issuer to finance projects or physical assets, and/or

D3.3.3 Related and supporting expenditures for projects or physical assets, where the projects or physical assets meet the relevant Sector Eligibility Criteria provided in Part $\mathrm{C}$ of the Climate Bonds Standard.

D3.3.4 Physical assets or projects include:

D3.3.4.1 Physical assets: existing and operational equipment, machinery, infrastructure, buildings or land;

D3.3.4.2 Projects: equipment, machinery, infrastructure and/or buildings in construction, redevelopment, (upgrades, expansion) and similar asset value creation or enhancement activity;

D3.3.5 Debt or other financing arrangements provided to finance projects or physical assets include:

D3.3.5.1 Capital expenditure undertaken to increase the value and/or lifetime of the physical assets or projects

D3.3.5.2 Acquisition costs/purchase price for an entity (company, division or similar) which holds physical assets or projects or share thereof which approximately corresponds to the Market Value of the physical asset or projects holdings; and

D3.3.5.3 Leasing structures resulting in Right of Use assets and liabilities ${ }^{9}$ and long leaseholds on land, buildings and infrastructure

D3.3.5.4 Loans and mortgages;

D3.3.5.5 Subsidies, tax and other incentives, credit schemes and grants, and other similar arrangements provided by public entities or agencies, including local and national governments.

D3.3.6 Related and supporting expenditure include:

D3.3.6.1 Relevant installation and routine maintenance expenditure and upgrades undertaken to maintain the value and/or lifetime of the asset; 
D3.3.6.2 Relevant performance monitoring costs with respect to tracking climate credentials (e.g. GHG emissions) and climate information services (e.g. satellite monitoring and emissions testing)

D3.3.6.3 Relevant research and development. training and program implementation costs and expenditures, where there is a definable future asset, product and/or process that can be linked to climate benefits under the relevant Sector Criteria.

D3.4 Nominated Projects \& Assets: Eligible Projects \& Assets that are associated with the bond, loan or other debt instrument. These projects or physical assets may be existing, under construction or yet to be deployed.

D3.5 Net Proceeds: The amount equal to the gross proceeds of the bonds, loans or other debt instruments minus issuance costs.

D3.6 Market Value: The price at which an asset would change hands between a willing buyer and a willing seller, neither being under any compulsion to buy or to sell and both having reasonable knowledge of relevant facts. This term is usually defined by convention within the relevant jurisdiction. It is sometimes called Fair Market Value, Market Value, or Fair Value, depending on the context.

\section{D4. Issuer documentation}

D4.1 Green Bond Framework: Information provided by the issuer which describes how the requirements in the Climate Bonds Standard will be met by the issuer for the relevant bond, loan or other debt instrument, or program of bonds, loans or other debt instruments. This information is often presented using the five core components of the Green Bond Principles (use of proceeds, selection of projects \& assets, management of proceeds, reporting, and external review). The contents of the Green Bond Framework are further defined in clause 4.1.

Note 1: The Green Bond Framework is an important part of the Certification Process. It is the primary reference for the verifier when undertaking the verification process and must be provided to the Climate Bonds Standard Board as one of the certification documents. See Part D of the Climate Bonds Standard for further detail on how the Green Bond Framework document is used in the Certification Process.

Note 2: Issuers are required to disclose their Green Bond Frameworks or relevant summaries to the market. This is in line with market best practice and also enables Certified Bonds to be eligible for key market indices, green bond funds and regional standards such as the proposed EU Green Bond Standard.

Note 3: Examples of Green Bond Framework documents are available on the Climate Bonds Initiative website.

D4.2 Disclosure Documentation: Documentation associated with the issuance of a bond, loan or other debt instrument; that is prepared before a bond, loan or other debt instrument is issued or entered into; and is made available to potential investors.

For bond issuance this includes legal documentation such as the Prospectus or the Final Terms.

Note: This documentation is usually required by the relevant financial regulatory body in the jurisdiction where the bond, loan or other debt instrument is being offered and may include items such as a prospectus, term sheet, offering, indenture contract, official bond statement, or legal documentation. In some jurisdictions this also includes marketing materials for the deal. 
D4.3 Update Report: A document prepared by the issuer that confirms the ongoing conformance of the issuer and the relevant bond, loan or other debt instrument, or program of bonds, loans or other debt instruments with the Post-Issuance Requirements of the Climate Bonds Standard. Update Reports contain three different types of reporting:

D4.3.1 Allocation Reporting - confirming the allocation of Net Proceeds to Nominated Projects \& Assets;

D4.3.2 Eligibility Reporting - confirming, where required by relevant Sector Eligibility Criteria, the characteristics or performance of Nominated Projects \& Assets required to conform to the relevant eligibility requirements under Part $C$ of the Climate Bonds Standard.

D4.3.3 Impact Reporting - disclosure of metrics or indicators which reflect the expected or actual impact of Nominated Projects \& Assets.

Note 1: The format and frequency of the Update Report will depend on the specific circumstances of the issuer and the relevant bond, loan or other debt instrument, or program. Further detail on the Update Report is provided in clause 8 of the Climate Bonds Standard. A suggested template for Update Reports is available on the Climate Bonds Initiative website.

Note 2: The proposed EU Green Bond Standard identifies two types of reporting; Allocation Reporting and Impact Reporting. The EU GBS definition of Impact Reporting includes the Climate Bonds Standard definitions of Eligibility and Impact Reporting.

D4.4 Climate Bond Information Form: A template document to be completed by the Issuer and submitted to the Climate Bonds Standard Secretariat as part of the Certification Process.

Note: The Climate Bond Information Form is available from the Climate Bonds Initiative website. The form is used and updated throughout the Certification Process

D4.5 Certification Agreement: A legal agreement which must be executed by the Issuer and submitted to the Climate Bonds Standard Board as part of the Certification Process.

Note: The Certification Agreement is available from the Climate Bonds Initiative website and includes terms and conditions for use of the Certification Mark. Adjustments to the template agreement can be negotiated directly with the Climate Bonds Standard Secretariat.

\section{D5. Approved Verifiers}

D5.1 Verifier: An independent third-party assurance provider or auditor, which has been approved by the Climate Bonds Standard Board and is listed on the Climate Bonds Initiative website as an Approved Verifier.

D5.2 Verifier's Report: A report prepared by the Verifier and provided by the Verifier to the Issuer. The Verifier's Report is then provided to the Climate Bonds Standard Secretariat as part of the Certification Process. The Verifier's Report must be prepared in line with the Guidance for Verifiers which is available from the Climate Bonds Initiative website. 


\section{Climate Bonds Standard}

The Climate Bonds Standard sets out the requirements to be met for Issuers seeking Certification of a bond, loan or other debt instrument. The requirements are separated into Pre-Issuance Requirements and Post-Issuance Requirements.

The Pre-Issuance Requirements need to be met by Issuers seeking Certification prior to Issuance. Post-Issuance Requirements need to be met by Issuers seeking continued Certification following Issuance of the bond, loan or other debt instrument.

In this document, there are some words with very specific meanings, which follows the conventions associated with development of international standards. The word "shall" indicates that a requirement must be met for Certification to be awarded. The word "should" indicates a recommendation; "may" indicates a permission; "can" indicates a possibility or a capability. "Note" is for guidance in understanding or clarifying the associated requirement. The word "Bond" is used in the requirements to represent a bond, loan or other debt instrument.

\section{Part A: Pre-Issuance Requirements}

This section of the Climate Bonds Standard sets out the requirements that apply to all Certified Climate Bonds, Certified Climate Loans and Certified Climate Debt Instruments prior to the issuance or closing of the bond, loan or other debt instrument. These requirements are designed to ensure that:

- the Issuer has established appropriate internal processes and controls prior to issuance or closing of the bond, loan or other debt instrument; and

- these internal processes and controls are sufficient to enable conformance with the Climate Bonds Standard after the bond, loan or other debt instrument has been issued or has closed, and allocation of the proceeds is underway; and

- the Issuer has provided a Green Bond Framework document which confirms its conformance with the Pre-Issuance Requirements of the Climate Bonds Standard.

For Issuers seeking Pre-Issuance Certification of their bond, loan or other debt instrument, all requirements set out in this section shall be met.

\section{Use of Proceeds}

1.1. The Issuer shall document the Nominated Projects \& Assets which are proposed to be associated with the Bond and which have been assessed as likely to be Eligible Projects \& Assets. The Issuer shall establish a list of Nominated Projects \& Assets which can be kept up-to-date during the term of the Bond.

1.2. The expected Net Proceeds of the Bond shall be no greater than the Issuer's total investment exposure to the proposed Nominated Projects \& Assets, or the relevant proportion of the total Market Value of the proposed Nominated Projects \& Assets which are owned or funded by the Issuer.

Note: The Issuer may choose whether to use its investment exposure or debt obligation to the Nominated Projects \& Assets or their Market Value when satisfying Clause 1.2. 
1.3. Nominated Projects \& Assets shall not be nominated to other Certified Climate Bonds, Certified Climate Loans, Certified Climate Debt Instruments, green bonds, green loans or other labelled instruments (such as social bonds or SDG bonds) unless it is demonstrated by the Issuer that:

1.3.1 distinct portions of the Nominated Projects \& Assets are being funded by different Certified Climate Bonds, Certified Climate Loans, Certified Climate Debt Instruments, green bonds, green loans or other labelled instruments; or,

1.3.2 the existing Certified Climate Bond, Certified Climate Loan or Certified Climate Debt Instrument is being refinanced via another Certified Climate Bond, Certified Climate Loan or Certified Climate Debt Instrument.

\section{Process for Evaluation and Selection of Projects \& Assets}

2.1. The Issuer shall establish, document and maintain a decision-making process which it uses to determine the eligibility of the Nominated Projects \& Assets. The decision-making process shall include, without limitation:

2.1.1. A statement on the climate-related objectives of the Bond;

2.1.2. How the climate-related objectives of the Bond are positioned within the context of the Issuer's overarching objectives, strategy, policy and/or processes relating to environmental sustainability;

\subsubsection{The Issuer's rationale for issuing the Bond;}

2.1.4. A process to determine whether the Nominated Projects \& Assets meet the eligibility requirements specified in Part $\mathrm{C}$ of the Climate Bonds Standard.

Note to 2.1: A wide variety of climate-related objectives are possible. These can vary from increasing the installed capacity of low carbon assets, such as solar power facilities, to having a specific objective focused on the operations or indirect effects of the projects \& assets, such as emissions reductions.

The climate-related objectives of the Bond, as stated by the Issuer, have implications for the reporting requirements under the Climate Bonds Standard. See Clauses 2.3, 5.2, 5.8, 6.1 .1 and 8.4 .

2.2. The Issuer should include under Clause 2.1 further aspects of the decision-making process, including:

2.2.1. related eligibility criteria, including, if applicable, exclusion criteria or any other process, applied to identify and manage potentially material environmental, social or governance risks associated with the Nominated Projects \& Assets.

2.2.2. any green standards or certifications referenced in the selection of Nominated Projects \& Assets.

2.3. The Issuer shall assess that all proposed Nominated Projects \& Assets to be associated with the Bond meet the documented objectives as stated under Clause 2.1.1 and are likely to conform to the relevant eligibility requirements under Part $\mathrm{C}$ of the Climate Bonds Standard. 


\section{Management of Proceeds}

3.1. The systems, policies and processes to be used for management of the Net Proceeds shall be documented by the Issuer and disclosed to the Verifier, and shall include arrangements for the following activities:

3.1.1. Tracking of proceeds: The Net Proceeds of the Bond can be credited to a sub-account, moved to a sub-portfolio, or otherwise tracked by the Issuer in an appropriate manner and documented.

3.1.2. Managing unallocated proceeds: The balance of unallocated Net Proceeds can be managed as per the requirements in Clause 7.3.

3.1.3. Earmarking funds to Nominated Projects \& Assets: An earmarking process can be used to manage and account for funding to the Nominated Projects \& Assets and enables estimation of the share of the Net Proceeds being used for financing and refinancing.

\section{Reporting Prior to Issuance}

4.1. The Issuer shall prepare a Green Bond Framework and make it publicly available prior to Issuance or at the time of Issuance. The Green Bond Framework shall include, without limitation:

4.1.1. Confirmation that the Bonds issued under the Green Bond Framework are aligned with the Climate Bonds Standard. This may include statements of alignment with other applicable standards, such as the EU Green Bond Standard, the ASEAN Green Bond Standard, Chinese domestic regulations, Japanese Green Bond Guidelines, etc.;

4.1.2. A summary of the expected use of proceeds, as defined under Clause 1.1, and the expected contribution of the relevant sectors or sub-sectors to the rapid transition required to achieve the goals of the Paris Climate Agreement;

4.1.3. A description of the decision-making process, as defined under Clause 2.1, with particular reference to the requirements in Clause 2.1.2;

4.1.4. Information on the methodology and assumptions to be used for: confirming, where required by relevant Sector Eligibility Criteria, the characteristics or performance of Nominated Projects \& Assets required to conform to the relevant eligibility requirements under Part C of the Climate Bonds Standard; and any other additional impact metrics that the issuer will define.

4.1.5. A summary of the approach to the management of unallocated Net Proceeds in accordance with Clause 3.1;

4.1.6. The intended approach to providing Update Reports to reaffirm conformance with the Climate Bonds Standard while the Bond remains outstanding;

4.1.7. The list of proposed Nominated Projects \& Assets associated with the Bond and the investment areas, as provided in Clause 9.1, into which the Nominated Projects \& Assets fall. Where there are limits on the amount of detail that can be made available about specific Nominated Projects \& Assets, information shall be presented on the investment areas which the Nominated Projects \& Assets fall into, as provided in Clause 9.1, and the Issuer shall provide an explanation of why detail on Nominated Projects \& Assets is limited; 
4.1.8. Where a proportion of the Net Proceeds are used for refinancing, an estimate of the share of the Net Proceeds used for financing and refinancing, and the relevant Nominated Projects \& Assets or investment areas which may be refinanced. This may also include the expected look-back period for refinanced Nominated Projects \& Assets.

Note: Issuers are encouraged to disclose as much information as possible with respect to Nominated Projects \& Assets. However, in many cases it is not possible for the Issuer to disclose detailed information about specific projects \& assets prior to the issuance of the Bond. This limitation may be due to confidentiality arrangements with owners of projects $\&$ assets, the dynamic nature of the project portfolio, competitive considerations, or other legal provisions which limit the disclosure of detailed information.

\subsection{The Issuer shall include in the Disclosure Documentation:}

4.2.1. The investment areas, as provided in Clause 9.1, into which the Nominated Projects \& Assets fall;

4.2.2. The intended types of temporary investment instruments for the management of unallocated Net Proceeds in accordance with Clause 7.3;

4.2.3. The Verifier engaged by the Issuer for the mandatory verification engagements;

4.2.4. The intended approach to providing Update Reports to reaffirm conformance with the Climate Bonds Standard while the Bond remains outstanding, including the location of the published documents;

4.2.5. The Climate Bonds Initiative Disclaimer provided in the Certification Agreement.

Note to 4.2.4: Issuers are encouraged to provide their Update Reports through existing reporting channels for the bond markets, such as the Electronic Municipal Market Access (EMMA) website for the US Municipality sector. 


\section{Part B: Post-Issuance Requirements}

This Section of the Climate Bonds Standard sets out the requirements that apply to all Certified Climate Bonds, Certified Climate Loans and Certified Climate Debt Instruments after the issuance of the bond or closing of the loan or other debt instrument. For Issuers seeking Post-Issuance Certification, all requirements set out in this section shall be met.

Issuers seeking Certification of bonds, loans or other debt instruments which have already been issued or closed, and were not Certified at the pre-issuance stage, need to prepare a Green Bond Framework (see Clause 4.1) and meet all of the Post-Issuance Requirements to receive Certification under the Climate Bonds Standard.

\section{Use of Proceeds}

5.1. The Net Proceeds of the Bond shall be allocated to the Nominated Projects \& Assets.

5.2. All Nominated Projects \& Assets shall meet the documented objectives of the Bond as stated under Clause 6.1.1 and shall be in conformance with the requirements of Part C of the Climate Bonds Standard.

5.3. The Issuer shall allocate the Net Proceeds to Nominated Projects \& Assets within 24 months of issuance of the Bond, or the Issuer shall disclose in post-issuance reporting as per clause 8.3 the estimated timeline for allocation of net proceeds to Nominated Projects \& Assets. Net proceeds may be reallocated to other Nominated Projects \& Assets at any time while the Bond remains outstanding.

5.4. Nominated Projects \& Assets shall not be nominated to other Certified Climate Bonds, Certified Climate Loans, Certified Climate Debt Instruments, green bonds, green loans or other labelled instruments (such as social bonds or SDG bonds) unless it is demonstrated by the Issuer that:

5.4.1. distinct portions of the Nominated Projects \& Assets are being funded by different Certified Climate Bonds, Certified Climate Loans, Certified Climate Debt Instruments, green bonds, green loans or other labelled instruments or,

5.4.2. the existing Certified Climate Bond, Certified Climate Loan or Certified Climate Debt Instrument is being refinanced via another Certified Climate Bond, Certified Climate Loan or Certified Climate Debt Instrument.

5.5. Where a proportion of the Net Proceeds of the Bond are used for refinancing, the Issuer shall track the share of the Net Proceeds used for financing and refinancing and identify which Nominated Projects \& Assets may be refinanced. This may also include the expected look-back period for refinanced Nominated Projects \& Assets.

5.6. The Net Proceeds of the Bond shall be tracked by the Issuer following a formal internal process which is documented in accordance with Clause 3.1.

5.7. The Net Proceeds of the Bond shall be no greater than the Issuer's total investment exposure or debt obligation to the Nominated Projects \& Assets, or the relevant proportion of the total Market Value of the Nominated Projects \& Assets which are owned or financed by the Issuer.

Note: The Issuer may choose whether to use the investment exposure or debt obligation to the Nominated Projects \& Assets or their Market Value when satisfying Clause 5.7. 
5.8. Additional Nominated Project \& Assets may be added to, or used to substitute or replenish, the portfolio of Nominated Project \& Assets as long as the additional Nominated Project \& Assets are eligible under Part C of the Climate Bonds Standard and are consistent with the Bond's objective as set out in Clause 6.1.1.

5.8.1. Where additional Nominated Projects \& Assets are covered by Sector Eligibility Criteria which were not included in the scope of either the Pre-Issuance Verification or the Post-Issuance Verification engagements, the Issuer shall engage a Verifier to provide a Verifier's Report covering at least the conformance of the additional Nominated Projects \& Assets with the relevant Sector Eligibility Criteria under Part $\mathrm{C}$ of the Climate Bonds Standard.

Note: For example, if the objectives of a Certified Climate Bond are to finance a portfolio of solar power facilities in a region and it receives Certification on that basis, then the Issuer may have only used the Solar Eligibility Criteria as the basis for the selection process in their Green Bond Framework. If the Issuer later wishes to adjust the objectives and allocate Net Proceeds to an expanded range of Nominated Projects \& Assets, such as hydro power facilities, water infrastructure or forestry assets, then it will need to use the relevant Sector Eligibility Criteria in its selection processes. These Sector Eligibility Criteria may contain more complex eligibility criteria or technical requirements when compared to those considered during the initial Certification.

\section{Process for Evaluation and Selection of Projects \& Assets}

6.1. The Issuer shall document and maintain a decision-making process which it uses to determine the continuing eligibility of the Nominated Projects \& Assets. This includes, without limitation:

\subsubsection{A statement on the climate-related objectives of the Bond;}

6.1.2. How the climate-related objectives of the Bond are positioned within the context of the Issuer's overarching objectives, strategy, policy and/or processes relating to environmental sustainability;

\subsubsection{The Issuer's rationale for issuing the Bond;}

6.1.4. A process to determine whether the Nominated Projects \& Assets meet the eligibility requirements specified in Part $\mathrm{C}$ of the Climate Bonds Standard;

6.1.5. Other information provided by the Issuer as described in Clause 2.2.

\section{Management of Proceeds}

7.1. The Net Proceeds of the Bond shall be credited to a sub account, moved to a sub- portfolio or otherwise identified by the Issuer in an appropriate manner, and documented.

7.2. The Issuer of the Bond shall maintain the earmarking process to manage and account for allocation of Net Proceeds to the Nominated Projects \& Assets as described in Clause 3.1.3.

7.3. While the Bond remains outstanding, the balance of the tracked Net Proceeds shall be reduced by amounts allocated to Nominated Projects \& Assets. Pending such allocations to Nominated Projects \& Assets, the balance of unallocated Net Proceeds shall be: 
7.3.1. Held in temporary investment instruments that are cash, or cash equivalent instruments, within a Treasury function; or

7.3.2. Held in temporary investment instruments that do not include greenhouse gas intensive projects which are inconsistent with the delivery of a low carbon and climate resilient economy; or

7.3.3. Applied to temporarily reduce indebtedness of a revolving nature before being redrawn for investments or disbursements to Nominated Projects \& Assets.

\section{Reporting}

8.1. The Issuer shall prepare an Update Report at least annually while the Bond remains outstanding.

8.1.1. The Update Report shall be made available to holders of the Bond and to the Climate Bonds Standard Board.

8.1.2. The Update Report shall be made available to the public.

8.1.3. The Issuer should provide an Update Report to holders of the Bond on a timely basis in case of material developments.

Note 1: If the Update Report cannot be made available to the public, then the Certified Climate Bond can not be included in the green bond database compiled by Climate Bonds Initiative. This database is used by index providers and other market players and has minimum requirements for public disclosure (https://www.climatebonds.net/cbi/pub/ data/bonds).

Note 2: If the Update Report can not be made available to the public, then the Bond would not be aligned with the preposed EU Green Bond Standard and would not be able to claim such conformance.

Note 3: The timing of reporting under this clause can be aligned with the Issuer's schedule of regular reporting and does not need to follow the anniversary of the Certification or Issuance of the Bond.

Note 4: Issuers are encouraged to make the Update Reports available through existing reporting channels for the capital markets, such as the EMMA system for the US Municipality sector.

Note 5: Material developments could include, but not limited to, early repayment, change of control or acquisition, change of name, changes to the eligibility of assets and projects as well as any material amendments, supplements, and other updates to deal documents including during the life of the debt instrument (including any winding up process or enforcement).

\subsection{The Update Report:}

\subsection{1. shall include Allocation Reporting;}

8.2.2. shall include Eligibility Reporting, where Eligibility Reporting is relevant for the Nominated Projects \& Assets;

8.2.3. should include Impact Reporting. 
8.3. The Allocation Reporting shall include, without limitation:

8.3.1. Confirmation that the Bonds issued under the Green Bond Framework are aligned with the Climate Bonds Standard. This may include statements of alignment with other applicable standards, such as the proposed EU Green Bond Standard, the ASEAN Green Bond Standard, Chinese domestic regulations, Japanese Green Bond Guidelines, etc;

\subsubsection{A statement on the climate-related objectives of the Bond;}

8.3.3. The list of Nominated Projects \& Assets to which Net Proceeds have been allocated (or re-allocated);

\subsubsection{The amounts allocated to the Nominated Projects \& Assets;}

8.3.5. An estimate of the share of the Net Proceeds used for financing and refinancing, and which Nominated Projects \& Assets have been refinanced. This may also include the expected look-back period for refinancing Nominated Projects \& Assets;

\subsubsection{The geographical distribution of the Nominated Projects \& Assets.}

8.4. The Eligibility Reporting shall include, without limitation:

8.4.1. Confirmation that the Nominated Projects \& Assets continue to meet the relevant eligibility requirements specified in Part $C$ of the Climate Bonds Standard;

8.4.2. Information on the environmental characteristics or performance of Nominated Projects \& Assets which is prescribed by the relevant Sector Eligibility Criteria.

Note 1: Some Bonds have very stable allocation of proceeds and do not need to track any performance indicators to maintain the eligibility of the projects \& assets (such as financing for a single large-scale solar facility). This means that the Update Report provided by the Issuer each year can be very concise and simply restate the information from previous reports.

8.5. Where there are limits to the amount of detail that can be made available in the Update Report about specific Nominated Projects \& Assets (as per Clause 8.3), information shall be presented on the investment areas which the Nominated Projects \& Assets fall into, as provided in Clause 9.1. Issuers shall include in the Update Report an explanation of why detail on Nominated Projects \& Assets is limited.

8.6. The Impact Reporting shall, without limitation,

8.6.1. Provide the expected or actual outcomes or impacts of the Nominated Projects \& Assets with respect to the climate-related objectives of the Bond;

8.6.2. Use qualitative performance indicators and, where feasible, quantitative performance measures of the outcomes or impacts of the Nominated Projects \& Assets with respect to the climate-related objectives of the Bond;

8.6.3. Provide the methods and the key underlying assumptions used in preparation of the performance indicators and metrics. 
Note 1: Examples of quantitative performance measures of the outcomes of Nominated Projects \& Assets can include, but are not limited to: energy capacity installed, electricity generated, greenhouse gas emissions performance of buildings, number of passengers carried by public transport, number of electric vehicles manufactured, volume of waste water treated. Impact metrics and indicators can include but are not limited to: greenhouse gas emissions reduced/avoided, number of households provided with access to clean power, decrease in water use, reduction in number of cars required.

Note 2: Methods include but are not limited to the framework used and the calculation methodology, including if metrics are annual, annualised, and/or lifetime calculations. Both proprietary and institutional frameworks (e.g. the Harmonized Framework for Impact Reporting or the Nordic Public Sector Issuers Position Paper on Green Bond Impact Reporting) may be used, where by institutional frameworks may be referenced, whereas proprietary and new frameworks should be described in sufficient detail to allow assessment.

8.7. The Issuer shall make available to the public any Verifier Reports or other relevant material which supports the Update Report.

8.8. Information about the Nominated Projects \& Assets and the Management of Proceeds shall be provided to the Verifier and to the Climate Bonds Standard Board to support the assessment of conformance with the Climate Bonds Standard.

Note: The information provided to the Verifier and the Climate Bonds Standard Board may be subject to confidentiality arrangements as required by the Issuer. 
Figure 1. Certification Process for a bond, loan or other debt instrument

\section{1}

Issuer begins by preparing the bond

- Identify assets that meet the relevant sector criteria and compile supporting information

- Create Green Bond Framework setting out how proceeds of the bond will be used the Issuer's internal controls

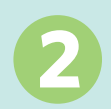

Engage a verifier

- Engage an Approved Verifier for Preand Post-Issuance Certification

- Provide them with relevant information

- Receive a Verifier's Report giving assurance that Climate Bonds Standard requirements are met

\section{Get Certified \& issue a} Certified Climate Bond

- Submit the Verifier's Report and Information Form to the Climate Bonds Initiative

- Receive a decision on Pre-Issuance Certification

- Issue the bond, using the Certified Climate Bond mark

\section{Confirm the Certification Post-Issuance}

- Within 24 months of issuance, submit the Verifiers Post-Issuance report

- Receive notification of Post-Issuance Certification

\section{5}

\section{Report annually}

- Prepare a simple report each year for term of the bond

- Provide it to bond holders and Climate Bonds Initiative

- Provide updates through public disclosure 


\section{Part C: Eligibility of Projects \& Assets}

This Part of the Climate Bonds Standard serves to determine the eligibility of specific projects and assets that, for the purposes of this Climate Bonds Standard, can be regarded as contributing to the rapid transition to a low carbon and climate resilient economy in line with the goals of the Paris Climate Agreement.

Clause 9 refers to the Climate Bonds Taxonomy. The taxonomy provides an overview of the mitigation and adaptation investment opportunities across the major sectors of the global economy. It serves as an initial screen for inclusions and exclusions for climate-aligned sectors and is used by the Climate Bonds Initiative when reviewing labelled bonds or loans for inclusion in its green bond list. The Taxonomy is available on the Climate Bonds Initiative resources webpage.

Clause 10 refers to detailed criteria, contained in the Sector Eligibility Criteria documents. The criteria contained in these documents must be met for projects and assets to be considered eligible. Sector Eligibility Criteria for a wide variety of projects and assets are available on the Climate Bonds Initiative resources website.

Some of the Sector Eligibility Criteria include requirements for the ongoing demonstration of eligibility via metrics or performance indicators over time, while other Sector Eligibility Criteria simply refer to the inherent characteristic of the assets.

At the time of publication of Version 3.0 of the Climate Bonds Standard (this document), Sector Eligibility Criteria are available for projects \& assets in wind energy, solar energy, geothermal energy, marine renewable energy, bioenergy, low carbon buildings, low carbon transport, water infrastructure, forests, land conservation and waste management.

Further Eligibility Criteria are being prepared covering shipping, hydro power, power grids, agriculture, energy efficient devices and industrial assets.

\section{Climate Bonds Taxonomy}

9.1. Nominated Projects \& Assets, as identified by the Issuer under Clauses 1.1 and 5.1, shall fall into one or more of the investment areas listed as included in the Climate Bonds Taxonomy.

\section{Sector Eligibility Criteria}

10.1. Nominated Projects \& Assets shall meet the specific eligibility requirements provided in the relevant Sector Eligibility Criteria documents. If there are different versions of the relevant Sector Eligibility Criteria documents, then the version which was current at issuance of the bond may be used for demonstration of the eligibility of Nominated Projects \& Assets for the duration of the bond.

Note: All Sector Eligibility Criteria are approved by the Climate Bonds Standard Board following a criteria development process involving Technical Working Groups, Industry Working Groups and stakeholder consultation. Further details on the development process and the sector-bysector criteria are available from the Climate Bonds Initiative resources webpage. 


\section{Part D: Certification under the Climate Bonds Standard}

This section of the Climate Bonds Standard sets out the rules and procedures for Certification of bonds, loans or other debt instruments by the Climate Bonds Standard Board. Further detail on the process steps and administrative workflow for Certification is provided in Guidance documents available from the Climate Bonds Initiative website.

\section{Outline of the Certification Process}

The Certification Process has three distinct phases that are aligned with the normal process for issuing and maintaining a bond, loan or other debt instrument. This allows the Certification Mark to be used during the pricing and marketing of the bond or the negotiation of the loan or other debt instrument. It also ensures that the integrity of the Certification Mark is maintained after issuance or closing of the bond, loan or other debt instrument and the allocation of net proceeds.

1. Pre-Issuance Certification: Assessment and Certification of the Issuer's internal processes, including its selection process for projects \& assets, internal tracking of proceeds, and the allocation system for net proceeds.

This phase includes the Issuer preparing a Green Bond Framework and a list of eligible projects \& assets; verification of the framework and the list by an Approved Verifier; production of a Verifier's Report; and provision of certification documents to the Climate Bonds Standard Secretariat.

Pre-Issuance Certification of bonds, loans or other debt instruments is awarded via a formal letter and a Certificate from the Climate Bonds Standard Board. The PreIssuance Certification covers the period prior to issuance or closing of the bond and can assist with marketing of the deal. Pre-Issuance Certification is valid until PostIssuance Certification is awarded.

2. Post-Issuance Certification: Assessment and Certification of the bond, loan or other debt instrument after it has been issued or has closed. If the bond, loan or other debt instrument has been awarded Pre-Issuance Certification, then the Post-Issuance Certification must be undertaken within 24 months of the date of financial close for the bond, loan or other debt instrument.

This phase includes preparation of post-issuance updates; verification of the information by an Approved Verifier; production of a Verifier's Report; and provision of certification documents to the Climate Bonds Standard Secretariat.

Post-Issuance Certification of individual bonds, loans or other debt instruments is confirmed via a formal letter from the Climate Bonds Standard Board. Post-Issuance Certification is awarded as at a particular date after the bond, loan or other debt instrument has been issued or has closed.

3. Ongoing Certification: Maintenance of the Certification based on ongoing conformance with the Post-Issuance Requirements of the Climate Bonds Standard, including meeting annual reporting requirements which are specified in Clause 8. Maintenance requirements and Non-conformance provisions are detailed in Clauses P10 and P11.

Programmatic Certification is also available for Issuers with large portfolios of Eligible Projects \& Assets and programs for issuance of multiple Certified deals over a number of years. The Programmatic Certification approach enables frequent issuers to have greater flexibility with respect to the timing and scale of issuing Certified Climate Bonds, Certified Climate Loans, or Certified Climate Debt Instruments. 
Issuers using Programmatic Certification have a reduced verification burden during the certification and issuance process within their program. Annual verification by an Approved Verifier is mandatory under Programmatic Certification. This option is described in detail in Clause P9.

If a bond, loan or other debt instrument has already been issued or has already closed, the Issuer can still seek Certification from the Climate Bonds Standard Board. Certification of existing bonds, loans or other debt instruments follows the PostIssuance Certification Process and is encouraged for existing Issuers which are aligned with the Climate Bonds Taxonomy.

The rules and the requirements for the Certification Process are provided in this document under the next section.

Certification documents can be submitted to the Climate Bonds Standard Board via the Climate Bonds Standard Secretariat at the email address: certification@climatebonds.net.

Further support is available via phone, email and the Climate Bonds Initiative website to assist Issuers, Verifiers and advisors with successfully navigating the requirements of the Climate Bonds Standard and the Certification Process.

\section{Pre-Issuance Climate Bond Certification}

\section{P1. Preparing for the certification process}

P1.1. Issuers seeking Certification and the use of the Certification Mark for a Bond prior to Issuance shall:

P1.1.1. Prepare a Green Bond Framework (or equivalent document) which describes how each of the requirements in the Climate Bonds Standard will be met by the Issuer for the relevant Bond or program of Bonds.

P1.1.2. Complete the Climate Bonds Information Form (as appropriate) and submit the completed form to the Climate Bonds Standard Secretariat.

Note 1: The Climate Bonds Information Form is available from the Climate Bonds Initiative resources webpage.

P1.2. The Issuer shall identify within the Climate Bonds Information Form what components of the information provided are confidential and what components can be publicly disclosed on the Climate Bonds Initiative website once Certification has been confirmed and Issuance of the Bond has been completed.

Note 2: The Issuer may submit a draft or incomplete Climate Bonds Information Form to the Climate Bonds Standard Secretariat in order to seek feedback and guidance on the requirements of the Climate Bonds Standard, the Sector Eligibility Criteria and the Certification Process.

Note 3: While acknowledging that some information is sensitive and not able to be disclosed publicly, the Climate Bonds Initiative will always encourage Issuers to provide as much public information as is possible. This is in line with market best practice and will also enable Bonds to be eligible for key market indices and green bond funds. For example, some major green bond index providers undertake a review of the Issuer's Green Bond Framework as part of their analysis and inclusion screening, while an increasing number of stock exchanges provide enhanced visibility though green bond segments but require adherence to green bond guidelines/requirements, which typically include disclosure of the Issuer's Green Bond Framework and external reviews (including Certification under the Climate Bonds Standard). 


\section{P2. Use of a Verifier Prior to Issuance}

P2.1. Issuers seeking Certification and the use of the Certification Mark for a Bond prior to its Issuance shall engage a Verifier to undertake either:

P2.1.1. An assurance engagement of the Issuer's and the proposed Bond's conformance with the Pre-Issuance Requirements of the Climate Bonds Standard. The Verifier shall issue an assurance report expressing a conclusion or an opinion as to whether the Issuer and the proposed Bond have conformed to the PreIssuance requirements of the Climate Bonds Standard; or

P2.1.2. An agreed-upon procedures engagement to assess the Issuer's and the proposed Bond's conformance with the Pre-Issuance Requirements of the Climate Bonds Standard. The Verifier shall consider the Readiness Assessment Protocol provided on the Climate Bonds Initiative website and shall issue a report of factual findings providing the assessment of the Issuer's and the proposed Bond's conformance with the Pre-Issuance Requirements of the Climate Bonds Standard.

P2.2. The subject matter considered by the Verifier shall include those requirements set out in the Pre-Issuance Requirements section of the Climate Bonds Standard, including the relevant Sector Eligibility Criteria.

P2.3. The Verifier shall undertake the engagement and prepare the Verifier's Report in line with the Guidance for Verifiers provided on the Climate Bonds Initiative website.

P2.4. The Verifier's Report shall include a summary of how the Issuer and the proposed Bond have conformed with each of the four components of the Pre-Issuance Requirements of the Climate Bonds Standard, including the relevant Sector Eligibility Criteria.

\section{P3. Applying for Pre-Issuance Certification}

P3.1. An Issuer that has completed a Pre-Issuance Assurance Engagement or AgreedUpon Procedures Engagement may apply to the Climate Bonds Standard Board to receive Certification of the Bond under the Climate Bonds Standard.

P3.2. The Issuer shall supply the Climate Bonds Standard Board with:

P3.2.1. a completed (as appropriate) Climate Bond Information Form,

P3.2.2. the Green Bond Framework (or equivalent summary),

P3.2.3. the Verifier's Report, and

P3.2.4. an executed Certification Agreement.

These documents shall be submitted to the Climate Bonds Standard Secretariat via email (certification@climatebonds.net).

\section{P4. Pre-Issuance Certification}

P4.1. If the Climate Bonds Standard Board is satisfied that the Issuer and proposed Bond are in conformance with the Pre-Issuance Requirements, then it shall provide a statement which confirms the Certification of the Bond under the Climate Bonds Standard. The Issuer then has the right (subject to the Certification Agreement) to use the Certification Mark in association with the relevant Bond until the PostIssuance Certification is confirmed. 
P4.2. An Issuer shall stop using the Certification Mark:

P4.2.1. Within two years of Issuance, unless the Issuer has received confirmation of Post-Issuance Certification from the Climate Bonds Standard Board; or is using Programmatic Certification as per Clause P9.

Note: The Certification at the pre-issuance stage is only valid for two years from the Issuance of the Certified Climate Bond, Certified Climate Loan or Certified Climate Debt Instrument. Post-issuance Certification must be confirmed within that timeframe for the continuing use of the Certification Mark.

P4.2.2. Where the Issuer no longer wishes to take the proposed Bond to Issuance and provides a written statement to that effect to the Climate Bonds Standard Board.

P4.2.3. Where the Issuer becomes aware that the Bond no longer conforms with the Climate Bonds Standard; and

P4.2.4. Where an Assurance Engagement commissioned by the Issuer or the Climate Bonds Standard Board finds that the Bond no longer conforms with the Climate Bonds Standard.

\section{Post-Issuance Certification}

\section{P5. Preparation for Post-Issuance Certification}

P5.1. Issuers seeking Certification and the use of the Certification Mark after Issuance of the Bond shall:

P5.1.1. If Pre-Issuance Certification has previously been confirmed for the Bond, update the Green Bond Framework and Climate Bond Information Form to reflect relevant changes or clarifications to this information after Issuance of the Bond.

P5.1.2. If Pre-Issuance Certification has not previously been confirmed, prepare a Green Bond Framework and other documents as described in Clauses P3.2 and P5.1.3.

P5.1.3. Prepare information and evidence to support the Bond's ongoing conformance with the Post-Issuance Requirements of the Climate Bonds Standard, including any ongoing requirements in the relevant Sector Eligibility Criteria.

\section{P6. Use of a Verifier for Post-Issuance Assurance}

P6.1. The Issuer shall engage a Verifier to undertake an Assurance Engagement after Issuance of the Bond.

P6.1.1. If Pre-Issuance Certification has previously been confirmed, then this Assurance Engagement must be completed within two years of the Issuance of the Bond.

P6.1.2. The subject matter considered by the Verifier shall include those requirements set out in the Post-Issuance Requirements section of the Climate Bonds Standard, including the relevant Sector Eligibility Criteria. 
P6.1.3. The Verifier shall undertake the engagement and prepare the report in line with the Guidance for Verifiers provided on the Climate Bonds Initiative website.

Note: The Issuer or other supporting entity should engage the same Verifier to undertake both the pre-issuance and post-issuance activities under the one commercial arrangement. However, this may not be possible in all circumstances.

P6.2. Verifier's Reports submitted to the Climate Bonds Standard Board shall be considered to be confidential unless the Issuer voluntarily discloses the Verifier's Report, or the Climate Bonds Standard Board is required by law or national regulators to disclose the Verifier's Report. The Climate Bonds Standard Board shall consult with the Issuer and Verifier on the presentation of the information prior to any public release of the Verifier's Report.

P6.3. The Verifier's Report shall include a summary of how the Issuer and the Bond have conformed with each of the four components of the Post-Issuance Requirements of the Climate Bonds Standard and the relevant Sector Eligibility Criteria.

\section{P7. Applying for Post-Issuance Certification}

P7.1. If Pre-Issuance Certification has previously been confirmed, the Issuer shall supply the Climate Bonds Standard Board with:

P7.1.1. an updated Climate Bond Information Form,

P7.1.2. the Green Bond Framework (or equivalent summary) as updated,

P7.1.3. the Verifier's Report from the Post-Issuance Assurance Engagement.

P7.2. If Pre-Issuance Certification has not previously been confirmed, the Issuer shall supply the Climate Bonds Standard Board with the documents listed in Clause P3.2.

These documents shall be submitted to the Climate Bonds Standard Secretariat via email (certification@climatebonds.net).

\section{P8. Post-Issuance Certification}

P8.1. If the Climate Bonds Standard Board is satisfied that the Issuer and the Bond are in conformance with the Post-Issuance Requirements of the Climate Bonds Standard, then it shall provide a statement that confirms the Certification of the Bond. The Issuer then has the right to continue using the Certification Mark in association with the relevant Bond (but no others) while the Bond remains outstanding.

P8.2. An Issuer shall stop using the Certification Mark if:

P8.2.1. Where the Issuer no longer wishes to continue with the Certification of the Bond and provides a written statement to that effect to the Climate Bonds Standard Board.

P8.2.2. It becomes aware that the Issuer and/or the Bond no longer conform with the Climate Bonds Standard; or

P8.2.3. An Assurance Engagement commissioned by the Issuer or the Climate Bonds Standard Board finds that the Issuer and/or the Bond no longer conform with the Climate Bonds Standard. 


\section{Programmatic Certification}

\section{P9. Programmatic Certification}

P9.1. An Issuer may use the option of Programmatic Certification if the Issuer:

P9.1.1. Can identify a large portfolio of Eligible Projects \& Assets which could cover issuance of multiple Certified Climate Bonds, Certified Climate Loans or Certified Climate Debt Instruments, and

P9.1.2. Has initiated a Program to issue multiple Certified deals over multiple years.

P9.2. For the first Bond under the Program, the Issuer shall follow the normal process for Climate Bond Certification as per clauses P1 to P8.

P9.3. For subsequent Bonds under the Program, the Issuer shall apply to the Climate Bonds Standard Board to receive Certification of each Bond's conformance with the Climate Bonds Standard by:

P9.3.1. Prior to Issuance, supplying the Climate Bonds Standard Board with a completed (as appropriate) Climate Bonds Information Form for the specific Bond to be considered for Certification. This document shall be submitted to the Climate Bonds Standard Secretariat who shall promptly provide the Issuer with Certification documents for the specific Bond.

P9.3.2. Following Issuance, supplying the Climate Bonds Standard Board with an updated Climate Bonds Information Form through the Climate Bonds Standard Secretariat.

P9.4. Every year after the first Issuance under the Program, the Issuer must engage a Verifier to undertake an Assurance Engagement

P9.4.1. The subject matter considered by the Verifier shall include those requirements set out in the Post-Issuance Requirements section of the Climate Bonds Standard, including the reporting requirements in Clause 8 , and shall cover all Bonds under the Program.

P9.4.2. The Issuer shall supply the Climate Bonds Standard Board with an updated Climate Bonds Information Form, the Green Bond Framework (if updated) and the Verifier's Report through the Climate Bonds Standard Secretariat.

\section{Maintaining Certification}

\section{P10. Maintaining Certification}

P10.1. To maintain the Certification status of the Bond the Issuer shall prepare and make available Update Reports at least annually while the Bond remains outstanding, as prescribed in the post-issuance reporting requirements in Clause 8 of the Climate Bonds Standard. The Update Report shall be signed by an authorised officer of the Issuer.

P10.2. The Issuer shall supply the Climate Bonds Standard Board with Update Reports through the Climate Bonds Standard Secretariat or share their location on a public website. Links to Update Reports will be published on the Climate Bonds Initiative website. 
P10.3. The Issuer may engage a Verifier to undertake further Assurance Engagements on a periodic basis (such as annually) to confirm that the Issuer and the Bond have maintained conformance with the Post-Issuance Requirements of the Climate Bonds Standard.

P10.4. Where Nominated Projects \& Assets are covered by Sector Eligibility Criteria which require ongoing demonstration of eligibility, the Issuer shall include in Update Reports confirmation that Nominated Projects \& Assets continue to meet the relevant criteria.

\section{P11. Non-Conformance}

P11.1. An Issuer using the Certification Mark shall provide further information if requested by the Climate Bonds Standard Board.

P11.2. In cases of claimed breach of conformance with the Climate Bonds Standard, the Climate Bonds Standard Board may request a new Verifier's Report be prepared by a different Verifier as a condition of maintaining Certification under the Climate Bonds Standard.

P11.2.1. This Verifier's Report shall be submitted to the Climate Bonds Standard Board for review within three months of the initial request.

P11.2.2. No more than one Verifier's Report in any six-month period shall be required to be provided by the Issuer following Post-Issuance Certification.

P11.3. Where a Certified Climate Bond, Certified Climate Loan or Certified Climate Debt Instrument is no longer in conformance with the Climate Bonds Standard, then the Issuer shall disclose that fact to the Climate Bonds Standard Board within one month of becoming aware of the non-conformance.

P11.3.1. The Climate Bonds Standard Board may suggest corrective actions for conformance to be restored.

P11.3.2. If conformance is not restored within an agreed time frame, the Climate Bonds Standard Board shall revoke its Certification of that Bond.

P11.4. Once Certification of a Bond has been revoked by the Climate Bonds Standard Board, the Issuer shall:

P11.4.1. Not use the Certification Mark in association with the Bond loan or imply that the Certification is still in place;

P11.4.2. Take all necessary steps to remove that Bond from relevant lists or indices which require Certification; and

P11.4.3. Inform the holders of the Bond, relevant exchanges, and other transaction parties of the change in Certification status of the Bond.

P11.5. An Issuer of a Bond which has had its Certification revoked by the Climate Bonds Standard Board may appeal the decision through the Climate Bonds Standard Appeals Mechanism, which is available from the Climate Bonds Initiative website. 


\section{Annex 1: Bonds, loans and other debt instruments which are eligible for Certification}

There is a wide variety of different financial structures of green bonds, green loans and other debt instruments which are eligible for Certification under the Climate Bonds Standard.

The term "Bond" is used in this Standard to describe the debt instrument being considered for Certification whether that be structured as a bond, a loan or some other form of debt instrument.

A green loan or green bond may take the form of one or more tranches of a bond or loan facility. In such cases, the green tranche(s) must be clearly designated.

The following types of debt instruments are eligible for Certification under the Climate Bonds Standard version 3.0:

Standard Use of Proceeds Bond: a standard recourse-to-the-issuer debt obligation which is either listed or unlisted.

Revenue Bond: a non-recourse-to-the-issuer debt obligation, either listed or unlisted, in which the credit exposure in the bond is to the pledged cash flows of the revenue streams, fees, taxes etc., and whose use of proceeds go to related or unrelated projects.

Project Bond: a project bond, either listed or unlisted, for a single or multiple projects for which the investor has direct exposure to the risk of the projects with or without potential recourse to the issuer.

Securitised Bond: a bond, either listed or unlisted, collateralised by one or more specific projects or assets, including lease, loan and other revenue receivables Asset Backed Securities ("ABS"), Mortgage Backed Securities ("MBS") including Agency MBS, Residential MBS, Commercial MBS, Commercial Mortgage Backed Securities (CMBS) Collateralised Loan Obligations ("CLO"), Collateralised Debt Obligations ("CDO"), Whole Business Securitisation ("WBS") and other securitisation structures.

Convertible Bonds or Notes: Bonds or notes, either listed or unlisted, which have the right but not the obligation to convert into a specified number of ordinary shares (or other securities) under specified terms and conditions. If the bond or note was Certified when it was issued and then later converted to equity, then its status as a Certified Climate Bond would end at the point of conversion.

Sukuk: refers to various types of quasi-debt securities that have been developed to meet the strictures of Islamic finance. One of the core principals underlying Islamic finance is avoiding the payment or collecting of interest. A variety of financial instruments have been created that serve the same purpose as bonds and other debt securities, but on which interest is not paid and investors share in profit distributions.

Schuldschein: a traditional German floating or fixed debt instrument. Some features of a Schuldschein are similar to those of loans, while other features are more similar to bonds.

Loan Facility: a credit line made available to borrowers to finance projects and assets which meet the relevant Sector Eligibility Criteria of the Climate Bonds Standard. Loans can be unsecured (with general recourse to the obligors) or secured (non-recourse or limited recourse to obligors). This includes: 
- Bilateral Loan: A loan agreement between one lender and the obligor(s)/ borrower(s)

- Syndicated /Club Loan: A loan from a number of different lenders acting together. The lenders form a syndicate and the borrower borrows from the syndicate. Common types of syndicated loans are underwritten deals, best-effort deals and club deals. Usually structured by one of several commercial banks or investment banks, can also include 'non-bank' lenders such as debt funds, insurance companies, hedge funds or pension funds.

- Revolving Credit Facilities, Export Credit Facilities and similar credit lines with a term of exceeding one year, where the parties to the loan must agree how the flow of funds will be evidenced.

Commercial Paper: Short-term debt securities. Unsecured promissory notes issued by strong credits including both financial institutions and non-bank corporates.

Debt Instruments issued by a Green Bond Fund: a Green Bond Fund is a fund which invests in green bonds based on a set of screens or criteria. Screens for the fund could include that the underlying projects and assets must meet the relevant Sector Eligibility Criteria of the Climate Bonds Standard. The fund is likely to issue securities such as units in a trust or use similarly structured arrangements to raise equity. Certification is only available for the debt instruments issued by the fund. The fund itself is not eligible for Certification under the Climate Bonds Standard.

Covered Bond (Pfandbriefe): a dual recourse bond which relies primarily on repayment from the issuesr, but also has access to a pool of assets (the cover pool). The cover pool often comprises mortgages, but other assets can be used as collateral too. For instance, the German Pfandbrief market includes Mortgages Pfandbrief, Public Pfandbrief, Ship and Aircraft Pfandbrief. In Luxembourg, it is possible to issue renewable infrastructure covered bonds.

Green Deposits: client funds held by a financial institution which are clearly identified and allocated to a portfolio of projects and assets which meet the relevant Sector Eligibility Criteria of the Climate Bonds Standard.

The following types of financial instruments are also eligible for Certification under the Climate Bonds Standard version 3.0:

Green Deposits: client funds held by a financial institution which are clearly identified and allocated to a portfolio of projects and assets which meet the relevant Sector Eligibility Criteria of the Climate Bonds Standard 


\section{Annex 2: Compatibility of Climate Bonds Standard V3.0 and the proposed EU Green Bonds Standard}

Version 3.0 of the Climate Bonds Standard has been developed to be fully compatible with the proposed European Union Green Bond Standard (EU GBS) which was released by the Technical Expert Group in June 2019.

Further detailed analysis of the proposed EU Green Bond Standard and the Climate Bonds Standard V3.0 documents and the associated requirements is available from the Climate Bonds Initiative website.

Table 1: Summary of the comparison between the draft EU Green Bond Standard and Climate Bonds Standard Version 3.0

\begin{tabular}{|c|c|c|}
\hline Key Feature & EU Green Bond Standard (draft) & Climate Bonds Standard Version 3.0 \\
\hline $\begin{array}{l}\text { Eligibility of } \\
\text { projects and } \\
\text { assets }\end{array}$ & $\begin{array}{l}\text { Based on the EU Taxonomy which includes } \\
\text { detailed criteria for relevant activities. } \\
\text { Climate change mitigation criteria are } \\
\text { aligned with achieving the goals of the } \\
\text { Paris Agreement. }\end{array}$ & $\begin{array}{l}\text { Based on the Climate Bonds Taxonomy } \\
\text { plus sector-by-sector Eligibility Criteria. } \\
\text { All criteria are aligned with achieving the } \\
\text { goals of the Paris Agreement. }\end{array}$ \\
\hline $\begin{array}{l}\text { Green Bond } \\
\text { Framework }\end{array}$ & $\begin{array}{l}\text { Green Bond Framework document must } \\
\text { be prepared as per specific re-quirements. } \\
\text { Mandatory disclosure of the Framework prior } \\
\text { to or at issuance. }\end{array}$ & $\begin{array}{l}\text { Green Bond Framework document } \\
\text { must be prepared as per specific } \\
\text { requirements. Mandatory disclosure of } \\
\text { the Framework prior to or at issuance. }\end{array}$ \\
\hline $\begin{array}{l}\text { Reporting prior to } \\
\text { issuance }\end{array}$ & $\begin{array}{l}\text { Legal documentation must include specific } \\
\text { information regarding the environmental } \\
\text { objective of the bond and use of proceeds. }\end{array}$ & $\begin{array}{l}\text { Legal documentation must include } \\
\text { specific information regarding the use } \\
\text { of proceeds, management of proceeds, } \\
\text { external reviewer and plans for report- } \\
\text { ing after issuance. }\end{array}$ \\
\hline $\begin{array}{l}\text { External review } \\
\text { prior to issuance }\end{array}$ & $\begin{array}{l}\text { Mandatory verification prior to issuance and } \\
\text { disclosure of verifier's report prior to or at } \\
\text { issuance. }\end{array}$ & $\begin{array}{l}\text { Mandatory verification prior to issuance } \\
\text { and disclosure of verifier's report prior to } \\
\text { or at issuance. }\end{array}$ \\
\hline $\begin{array}{l}\text { Reporting after } \\
\text { issuance }\end{array}$ & $\begin{array}{l}\text { Mandatory reporting with specific } \\
\text { requirements for contents of the report. } \\
\text { Annual reporting and disclosure is } \\
\text { mandatory up to full allocation of proceeds } \\
\text { and in case of any material change in } \\
\text { allocation of proceeds. } \\
\text { Defines } 2 \text { types of reporting: Allocation } \\
\text { and Impact. }\end{array}$ & $\begin{array}{l}\text { Mandatory reporting with specific } \\
\text { requirements for contents of the report. } \\
\text { Annual reporting and disclosure is } \\
\text { mandatory for the entire period the bond } \\
\text { remains outstanding. } \\
\text { Defines } 3 \text { types of reporting: Allocation, } \\
\text { Eligibility and Impact. }\end{array}$ \\
\hline $\begin{array}{l}\text { External review } \\
\text { after issuance }\end{array}$ & $\begin{array}{l}\text { Mandatory verification at least once } \\
\text { after issuance and must be at or after full } \\
\text { allocation of proceeds. Mandatory disclosure } \\
\text { of verifier's report. }\end{array}$ & $\begin{array}{l}\text { Mandatory verification at least once } \\
\text { after issuance, within two years of } \\
\text { is-suance. Mandatory disclosure of } \\
\text { verifier's report. }\end{array}$ \\
\hline $\begin{array}{l}\text { Status of external } \\
\text { reviewers }\end{array}$ & $\begin{array}{l}\text { Must be Registered under the Voluntary } \\
\text { Interim Registration Scheme. }\end{array}$ & $\begin{array}{l}\text { Must be listed as an Approved Verifier } \\
\text { on the Climate Bonds Initiative website. }\end{array}$ \\
\hline $\begin{array}{l}\text { Labelling of } \\
\text { existing bonds }\end{array}$ & $\begin{array}{l}\text { Allowed, with mandatory verification and } \\
\text { disclosure of key documents. }\end{array}$ & $\begin{array}{l}\text { Allowed, with mandatory verification } \\
\text { and disclosure of key documents. }\end{array}$ \\
\hline
\end{tabular}




\section{Annex 3: Certification and the CBI Green Bond Database}

The Climate Bonds Initiative maintains a comprehensive Green Bond Database which is used by index providers and other market players. The compilation and maintenance of dataset is governed by the CBI Green Bond Database Methodology. The latest version of this document is available from the CBI website.

The Methodology document provides a detailed description of the screening process and rules for inclusion. Certification under the Climate Bonds Standard means that eligible debt instruments are automatically included in the Green Bond Database. However, not all Certified debt instruments are eligible to be included in the Database.

The relevant provisions for inclusion in the $\mathrm{CBI}$ Green Bond Database are outlined below.

\section{Types of debt instruments}

Debt instruments issued by a Green Bond Fund are not eligible for inclusion in the $\mathrm{CBI}$ green bond database to avoid double-counting. Such instruments are considered "repackaging" of existing green bonds.

Green Deposits products are not eligible for inclusion in the CBI green bond database as they are not debt instruments and will typically lack a fixed amount to be raised under the program and specific issue date.

\section{Minimum term / duration}

Instruments with an original term of less than one year are eligible for inclusion in the $\mathrm{CBI}$ green bond database.

\section{Disclosure after issuance}

Within 30 days of closing the Certified Climate Bond, Certified Climate Loan or other Certified debt instrument, the Issuer/Borrower should notify Climate Bonds Initiative of this and provide the following minimum information on the debt instrument: (1) amount issued with currency of issue, (2) date of issue, and (3) maturity date. If this information is not available to $\mathrm{CBI}$ then the instrument is not eligible for inclusion in the $\mathrm{CBI}$ green bond database. 


\section{Climate Bonds}

